\title{
Locomotor stability and adaptation during perturbed walking across the adult female lifespan
}

Citation for published version (APA):

McCrum, C., Epro, G., Meijer, K., Zijlstra, W., Brueggemann, G-P., \& Karamanidis, K. (2016). Locomotor stability and adaptation during perturbed walking across the adult female lifespan. Journal of Biomechanics, 49(7), 1244-1247. https://doi.org/10.1016/j.jbiomech.2016.02.051

Document status and date:

Published: 03/05/2016

DOI:

10.1016/j.jbiomech.2016.02.051

Document Version:

Publisher's PDF, also known as Version of record

Document license:

Taverne

Please check the document version of this publication:

- A submitted manuscript is the version of the article upon submission and before peer-review. There can be important differences between the submitted version and the official published version of record.

People interested in the research are advised to contact the author for the final version of the publication, or visit the DOI to the publisher's website.

- The final author version and the galley proof are versions of the publication after peer review.

- The final published version features the final layout of the paper including the volume, issue and page numbers.

Link to publication

\footnotetext{
General rights rights.

- You may freely distribute the URL identifying the publication in the public portal. please follow below link for the End User Agreement:

www.umlib.nl/taverne-license

Take down policy

If you believe that this document breaches copyright please contact us at:

repository@maastrichtuniversity.nl

providing details and we will investigate your claim.
}

Copyright and moral rights for the publications made accessible in the public portal are retained by the authors and/or other copyright owners and it is a condition of accessing publications that users recognise and abide by the legal requirements associated with these

- Users may download and print one copy of any publication from the public portal for the purpose of private study or research.

- You may not further distribute the material or use it for any profit-making activity or commercial gain

If the publication is distributed under the terms of Article $25 \mathrm{fa}$ of the Dutch Copyright Act, indicated by the "Taverne" license above, 
Short communication

\title{
Locomotor stability and adaptation during perturbed walking across the adult female lifespan
}

\author{
Christopher McCrum ${ }^{\mathrm{a}, \mathrm{b}}$, Gaspar Epro ${ }^{\mathrm{b}, \mathrm{c}}$, Kenneth Meijer ${ }^{\mathrm{a}}$, Wiebren Zijlstra ${ }^{\mathrm{b}}$, \\ Gert-Peter Brüggemann ${ }^{\mathrm{c}}$, Kiros Karamanidis ${ }^{\mathrm{b}, *}$ \\ ${ }^{a}$ NUTRIM School of Nutrition and Translational Research in Metabolism, Maastricht University Medical Centre+, Department of Human Movement Science, \\ Maastricht, The Netherlands \\ ${ }^{\mathrm{b}}$ Institute of Movement and Sport Gerontology, German Sport University Cologne, Germany \\ ${ }^{\mathrm{c}}$ Institute of Biomechanics and Orthopaedics, German Sport University Cologne, Germany
}

\section{A R T I C L E I N F O}

\section{Article history:}

Accepted 26 February 2016

\section{Keywords:}

Age

Aftereffects

Dynamic gait stability

Elderly

Falls

Motor learning

\begin{abstract}
A B S T R A C T
The aim of this work was to examine locomotor stability and adaptation across the adult female lifespan during perturbed walking on the treadmill. 11 young, 11 middle and 14 older-aged female adults (mean and SD: 25.5(2.1), 50.6(6.4) and 69.0(4.7) years old respectively) walked on a treadmill. We applied a sustained perturbation to the swing phase of the right leg for 18 consecutive gait cycles, followed by a step with the resistance unexpectedly removed, via an ankle strap connected to a break-and-release system. The margin of stability (MoS) at foot touchdown was calculated as the difference between the anterior boundary of the base of support (BoS) and extrapolated center of mass. Older participants showed lower MoS adaptation magnitude in the early adaptation phase (steps 1-3) compared to the young and middle-aged groups. However, in the late adaptation phase (steps 16-18) there were no significant differences in adaptation magnitude between the three age groups. After removing the resistance, all three age groups showed similar aftereffects (i.e. increased BoS). The current results suggest that in old age, the ability to recalibrate locomotion to control stability is preserved, but the rate of adaptive improvement in locomotor stability is diminished.
\end{abstract}

(c) 2016 Elsevier Ltd. All rights reserved.

\section{Introduction}

Reducing falls in the elderly is vital for public health, due to consequences such as fractures, functional decline and death (Terroso et al., 2014). Older adults fall most often during ambulation, frequently due to tripping or slipping (Talbot et al., 2005). Reactive and predictive adjustments of gait contribute to locomotor stability (state of the center of mass (CoM) in relation to the base of support (BoS)) and decrease the risk of falling when facing a challenging walking environment (Bierbaum et al., 2010, 2011). One such adjustment is rapid stepping, which is diminished in old age (Maki and Mcllroy, 2006). Step length and time following release from a forward lean indeed predict older adults' maximum recoverable forward lean angle (Graham et al., 2015), which predicts future falls (Carty et al., 2015).

Improving compensatory stepping adjustments may help in preventing falls (Grabiner et al., 2014). In older adults, experiencing

\footnotetext{
* Correspondence to: Institute of Movement and Sport Gerontology, German Sport University Cologne, Am Sportpark Müngersdorf 6, 50933 Cologne, Germany. Tel.: +49221 4982 6144; fax: +49221 49826143 .

E-mail address: karamanidis@dshs-koeln.de (K. Karamanidis).
}

laboratory-induced gait perturbations has led to improved recovery responses to various mechanical perturbations (Bhatt et al., 2012; Bierbaum et al., 2010, 2011; Pai et al., 2010, 2014b). More importantly, perturbation training may reduce falls by up to $50 \%$ in the following year (Pai et al., 2014a; Rosenblatt et al., 2013). However, it remains partly unclear how locomotion adapts to control stability in response to perturbations, and how this ability declines across the adult lifespan. Determining how locomotor stability and adaptation are affected across the female lifespan is of particular importance, as locomotor stability declines, and falls increase in middle age in women (Süptitz et al., 2013; Talbot et al., 2005). Women over 45 have an increased susceptibility to bone fractures (Donaldson et al., 1990), and experience more fall-related injuries (Talbot et al., 2005) and hip fractures (Parkkari et al., 1999) than men.

Bruijn et al. (2012) found that older adults show diminished step length adaptation in response to a split-belt walking paradigm (one belt at $1 \mathrm{~m} / \mathrm{s}$, the other at $0.5 \mathrm{~m} / \mathrm{s}$ ) compared with younger adults. Bierbaum et al. (2010), however, found that older adults are capable of adapting their dynamic stability to a similar or greater magnitude as young adults to surface change perturbations. Additionally, Pai et al. (2010) showed that older adults are capable of predictive and reactive adaptations to slip perturbations. In general however, there 
is a lack of studies on aging and locomotor stability and adaptation and importantly, no study has analyzed how the adaptability of locomotion to perturbations is affected across the adult lifespan using a cross sectional design. This study aimed to examine locomotor stability and adaptation in young, middle and older-aged adults in response to a sustained resistance perturbation during walking, in order to test the hypothesis that older adults remain capable of adapting their locomotion to external gait perturbations in order to maintain stability, but not to the same extent as young and middle-aged adults.

\section{Methods}

Eleven young (mean and SD: 25.5(2.1) years), 11 middle-aged (50.6(6.4) years) and 14 older (69.0(4.7) years) healthy women, with no known musculoskeletal or neurological deficits, participated in this study. The height and body mass for each group were $166.9(4.3) \mathrm{cm}$ and $62.7(6.8) \mathrm{kg}$ for the young, $168.2(4.8) \mathrm{cm}$ and 66.4 (7.9) $\mathrm{kg}$ for the middle-aged, and $161.2(5.0) \mathrm{cm}$ and $67.3(4.7) \mathrm{kg}$ for the older adults respectively. Participants walked at $1.4 \mathrm{~m} / \mathrm{s}$ on a treadmill (pulsar $4.0, \mathrm{~h} / \mathrm{p} /$ cosmos; Nussdorf-Traunstein, Germany) to standardize the walking speed and perturbation. One treadmill walking familiarization session took place four to seven days before measurements. Participants wore a safety harness connected to an overhead frame during the measurements. The procedures were explained to the participants prior to obtaining informed consent in accordance with the Declaration of Helsinki. The study was approved by the German Sport University Cologne ethical board.

The gait perturbation was applied using a custom built brake-and-release system described previously (McCrum et al., 2014; Süptitz et al., 2013) which applies and removes $2.1 \mathrm{~kg}$ of resistance to the leg via an ankle strap and Teflon cable, controlled via an electronically driven magnet system. Resistance is turned on during the right leg stance phase and removed following right foot touchdown, so that the entire swing phase is affected. The measurement periods included familiarization, baseline, single perturbation, washout, sustained perturbation and post-perturbation. Familiarization consisted of ten minutes walking at $1.4 \mathrm{~m} / \mathrm{s}$. The ankle strap was then attached to the right leg and participants walked for a further four minutes. A baseline measurement (non-perturbed walking; approximately 20 seconds) was recorded at the end of this period. Six consecutive steps were used to determine a baseline for the assessed parameters. The resistance was then applied for one step and immediately removed. Following a two to three minute washout period of non-perturbed walking, the resistance was again applied, this time left on for 18 consecutive steps of the right leg, followed by a final step of the right leg with the resistance removed (post-perturbation), in order to examine aftereffects. Aftereffects were analyzed using the BoS, as recalibrations were expected to be most noticeable in this variable. Participants were not warned about the onset or removal of the perturbation, but were informed that a resistance would be applied at some point during walking.

Our method to assess gait stability on the treadmill has been described in previous studies (McCrum et al., 2014; Süptitz et al., 2012, 2013), and a detailed description is provided in the appendix (see Supplementary material). Briefly, a full kinematic model was tracked using 26 markers and an eight camera (120 Hz) Vicon Nexus motion capture system (Vicon Motion Systems, Oxford, UK). The anteroposterior margins of stability $(\mathrm{MoS})$ were calculated at foot touchdown (determined using tibia accelerometer data (ADXL250; Analog Devices, Norwood, MA USA)) as the difference between the anterior boundary of the BoS (anteroposterior component of the toe projection to the ground) and the extrapolated CoM as defined by Hof et al. (2005).

The parameters of interest were MoS at baseline, at touchdown of the perturbed step during the single perturbation period and of the first six and last five steps during the sustained perturbation period. This method was used due to recording limitations of the motion capture system, which could not record all 18 stride cycles. In order to examine locomotor adaptation, we calculated the MoS adaptation magnitude in a similar manner to Bierbaum et al. (2011) for the early and late adaptation phases of the sustained perturbation period as follows:

Adaptation Magnitude $=\left(1-\frac{\text { MoS }_{\text {AdaptPeriod }}-\text { MoS }_{\text {Base }}}{M o S_{\text {Single }}-M o S_{\text {Base }}}\right) \times 100$

where $M o S_{\text {AdaptPeriod }}$ is either the mean MoS of the first or last three perturbed steps (early or late adaptation period), $M o S_{\text {single }}$ is the MoS at touchdown of the perturbed step during the single perturbation period, and $M o S_{\text {Base }}$ is baseline MoS Finally, in order to examine aftereffects, we compared the BoS during baseline with the step after the unexpected removal of the resistance.

A two-way repeated measures ANOVA with age and step (baseline, single perturbation period step, and the first six and last five steps of the sustained perturbation period) as factors was used to examine age and step related differences in the MoS. Differences in adaptation magnitude were examined using a two-way repeated measures ANOVA with age and adaptation phase (early and late) as factors. To assess potential aftereffects in the BoS, a two-way repeated measures ANOVA with age group and task period (base and post-perturbation) as factors was conducted. Duncan's Tests were applied for pairwise comparisons. The significance level was $\alpha=0.05$. Results are presented as mean and standard error.

\section{Results}

A significant age by step interaction was found for the MoS $(p<0.05)$ indicating that the effect of age on the MoS was step specific (Fig. 1). Post-hoc tests revealed no significant differences between groups during baseline. During the single perturbation period, all groups demonstrated significantly lower MoS in comparison to baseline $(p<0.05)$ with no between age group differences. Significantly lower MoS compared to baseline was found for all groups for all steps in the sustained perturbation period $(p<0.05)$. The older age group demonstrated significantly lower MoS for the first six steps of the sustained perturbation period $(p<0.05)$ compared with the younger groups, however there were no significant differences in MoS between the age groups for the last five steps (steps $14-18 ; p>0.05$ ).

Regarding the adaptation magnitude, the ANOVA revealed a significant age by adaptation phase interaction ( $p<0.05$; Fig. 2). Post-hoc tests revealed significant differences between age groups only during the early adaptation phase, with the older group showing a significantly lower adaptation magnitude $(p<0.05$; Fig. 2). At touchdown of the final measured step with the resistance unexpectedly removed, significant aftereffects were seen in all groups, with a significantly increased $\operatorname{BoS}(p<0.05$; Fig. 3$)$ compared to baseline, with no significant differences found between the age groups ( $p>0.05$; Fig. 3 ).

\section{Discussion}

We aimed to examine locomotor stability and adaptation in response to a sustained perturbation in young, middle and olderaged female adults. Our hypothesis, that older adults remain capable of adapting to external gait perturbations, but not to the same extent as younger adults, was partly supported, as the older adults demonstrated a similar adaptation magnitude of the MoS to the young and middle-aged adults by the end of the sustained perturbation period. However, in the first three steps of the sustained perturbation period, the older adults showed significantly lower MoS adaptation magnitude compared to the young and middle-aged groups, suggesting that while they could adapt to a similar magnitude, this occurred slower than in the younger groups. This declined rate of adaptation was not present in middle-aged adults.

The MoS adaptation magnitude was significantly decreased in the early adaptation phase for the older group compared to the other groups. This indicates that adaptations made following the initial single perturbation were not as substantial in the older group as in the other groups, indicating a higher risk for older adults in situations with perturbations in quick succession (e.g. uneven terrain). That being said, all age groups demonstrated significant improvements in MoS adaptation magnitude by the late adaptation phase, suggesting that the locomotor adaptability was not diminished in any age group. Similar results were seen in the BoS, showing that older adults struggled to cope with the early perturbations (see Fig. S1 in the Supplementary material).

Our analysis of the aftereffects in the BoS support the role of a recalibration of locomotion in our participants, as all subject groups showed a significant increase in the BoS after the resistance was removed (Fig. 3). These findings suggest that the recalibration of motor commands may not be significantly affected by 


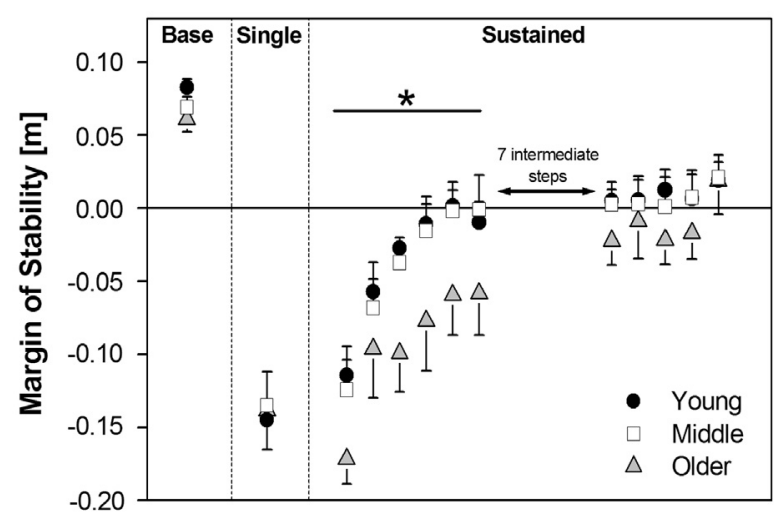

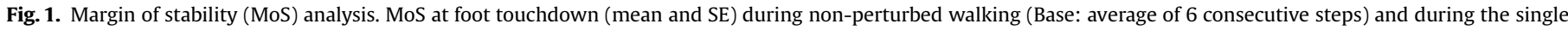

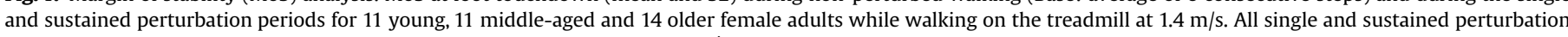

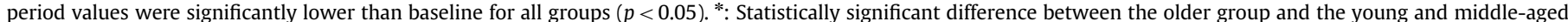
groups with no differences between the young and middle-aged groups $(p<0.05)$.

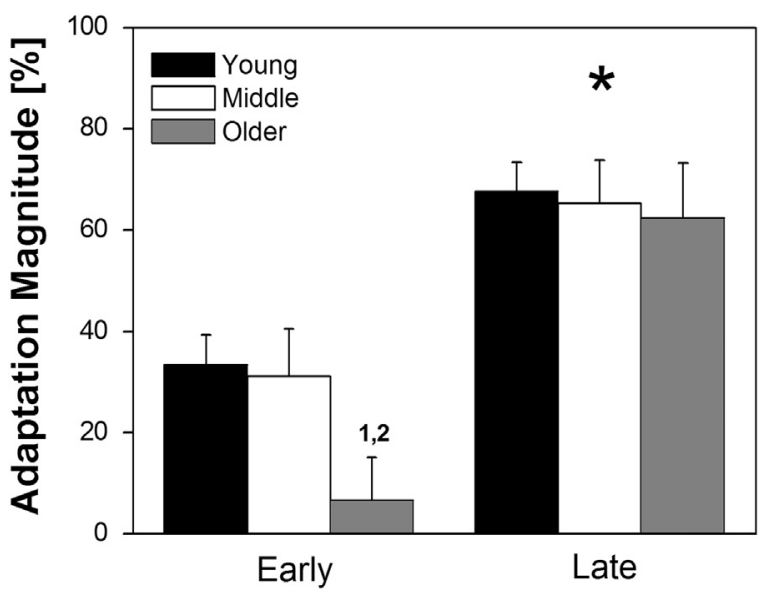

Fig. 2. Adaptation magnitude in MoS in the early and late adaptation phases. The adaptation magnitude for all groups in the early (first three steps) and late (last three steps) adaptation phases in MoS in reference to the single perturbation period. 1 And 2: statistically significant difference during the early adaptation period to the young and middle-aged groups respectively $(p<0.05) . *$ : Statistically significant difference to the early adaptation period for all groups $(p<0.05)$.

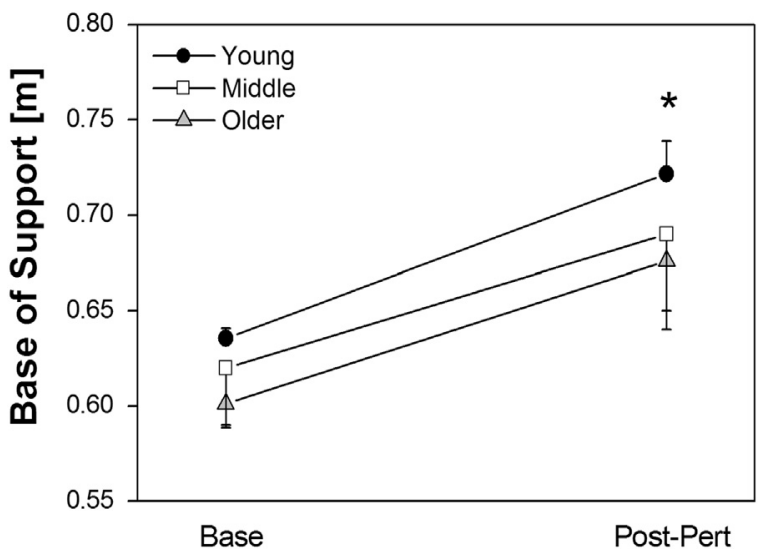

Fig. 3. Aftereffects in the BoS. The BoS for all age groups during non-perturbed walking (Base) and in the first step after the resistance was unexpectedly removed (Post-Pert). *: Statistically significant difference in the BoS between Post-Pert and Base for all groups $(p<0.05)$. aging, although adaptation may occur more quickly in younger than in older adults. The aftereffects indicate either, that older adults are able to retain adaptations after only a few perturbations, or that they demonstrate perseverance after resistance removal. However, to specifically investigate this, many more perturbations would be required, which due to the task's physical demand, was not considered feasible.

While Bruijn et al. (2012) reported deficient step length adaptation in older adults, their walking speed was substantially slower than our $1.4 \mathrm{~m} / \mathrm{s}$, which may not have required such significant adaptation rates or magnitudes to continue safe forward progression of gait. An additional consideration is the range of different perturbations used across studies, as these could have different effects on the magnitude of adaptations required to maintain stability. A final consideration is that we analyzed three age cohorts, and did not longitudinally follow participants as they grew older, and therefore, our conclusions should be interpreted with this in mind.

In conclusion, our results provide evidence that with aging, the ability to recalibrate locomotion to control stability is preserved. However, a deficient rate of locomotor adaptation can be seen in old age, which may have implications for training interventions and falls prevention.

\section{Conflict of interest statement}

The authors declare no conflicts of interest.

\section{Acknowledgments}

We thank Thomas Förster and Jürgern Geiermann and their teams for technical assistance. Funding was provided by the Forschungsservicestelle, German Sport University Cologne.

\section{Appendix A. Supplementary material}

Supplementary data associated with this article can be found in the online version at http://dx.doi.org/10.1016/j.jbiomech.2016.02.051. 


\section{References}

Bhatt, T., Yang, F., Pai, Y.C., 2012. Learning to resist gait-slip falls: long-term retention in community-dwelling older adults. Arch. Phys. Med. Rehabil. 93 $557-564$.

Bierbaum, S., Peper, A., Karamanidis, K., Arampatzis, A., 2010. Adaptationa responses in dynamic stability during disturbed walking in the elderly. J. Biomech. 43, 2362-2368.

Bierbaum, S., Peper, A., Karamanidis, K., Arampatzis, A., 2011. Adaptive feedback potential in dynamic stability during disturbed walking in the elderly. J. Biomech. 44, 1921-1926.

Bruijn, S.M., Van Impe, A., Duysens, J., Swinnen, S.P., 2012. Split-belt walking: adaptation differences between young and older adults. J. Neurophysiol. 108, 1149-1157.

Carty, C.P., Cronin, N.J., Nicholson, D., Lichtwark, G.A., Mills, P.M., Kerr, G., Cresswell, A.G., Barrett, R.S., 2015. Reactive stepping behaviour in response to forward loss of balance predicts future falls in community-dwelling older adults. Age Ageing 44, 109-115.

Donaldson, L.J., Cook, A., Thomson, R.G., 1990. Incidence of fractures in a geographically defined population. J. Epidemiol. Community Health 44 (3), 241-245.

Grabiner, M.D., Crenshaw, J.R., Hurt, C.P., Rosenblatt, N.J., Troy, K.L., 2014. Exercisebased fall prevention: can you be a bit more specific? Exerc Sport Sci Rev. 42 $161-168$.

Graham, D.F., Carty, C.P., Lloyd, D.G., Barrett, R.S., 2015. Biomechanical predictors of maximal balance recovery performance amongst community-dwelling older adults. Exp. Gerontol. 66, 39-46.

Hof, A.L., Gazendam, M.G., Sinke, W.E., 2005. The condition for dynamic stability. J. Biomech. 38, 1-8.

Maki, B.E., McIlroy, W.E., 2006. Control of rapid limb movements for balance recovery: age-related changes and implications for fall prevention. Age Ageing 35 (Suppl 2), ii12-ii18.

McCrum, C., Eysel-Gosepath, K., Epro, G., Meijer, K., Savelberg, H.H., Bruggemann, G.P., Karamanidis, K., 2014. Deficient recovery response and adaptive feedback potential in dynamic gait stability in unilateral peripheral vestibular disorder patients. Physiol. Rep. 2, e12222.

Pai, Y.C., Bhatt, T., Yang, F., Wang, E., 2014a. Perturbation training can reduce community-dwelling older adults' annual fall risk: a randomized controlled trial. J. Gerontol. A Biol. 69, 1586-1594.

Pai, Y.C., Yang, F., Bhatt, T., Wang, E., 2014b. Learning from laboratory-induced falling: long-term motor retention among older adults. Age 36, 9640.

Pai, Y.C., Bhatt, T., Wang, E., Espy, D., Pavol, M.J., 2010. Inoculation against falls: rapid adaptation by young and older adults to slips during daily activities. Arch. Phys. Med. Rehabil. 91, 452-459.

Parkkari, J., Kannus, P., Palvanen, M., Natri, A., Vainio, J., Aho, H., Vuori, I., Järvinen, M., 1999. Majority of hip fractures occur as a result of a fall and impact on the greater trochanter of the femur: a prospective controlled hip fracture study with 206 consecutive patients. Calcif Tissue Int. 65 (3), 183-187.

Rosenblatt, N.J., Marone, J., Grabiner, M.D., 2013. Preventing trip-related falls by community-dwelling adults: a prospective study. J. Am. Geriatr. Soc. 61, 1629-1631.

Süptitz, F., Karamanidis, K., Catala, M.M., Brüggemann, G.P., 2012. Symmetry and reproducibility of the components of dynamic stability in young adults at different walking velocities on the treadmill. J. Electromyogr. Kinesiol. 22, 301-307.

Süptitz, F., Catala, M.M., Brüggemann, G.P., Karamanidis, K., 2013. Dynamic stability control during perturbed walking can be assessed by a reduced kinematic model across the adult female lifespan. Hum. Mov. Sci. 32, 1404-1414.

Talbot, L.A., Musiol, R.J., Witham, E.K., Metter, E.J., 2005. Falls in young, middle-aged and older community dwelling adults: perceived cause, environmental factors and injury. BMC Public Health 5, 86 .

Terroso, M., Rosa, N., Marques, A.T., Simoes, R., 2014. Physical consequences of falls in the elderly: a literature review from 1995 to 2010. Eur. Rev. Aging Phys. Act. $11,51-59$. 